\title{
Modeling of most efficient channel form: a quantitative approach
}

\author{
Balai Chandra Das ${ }^{1}$
}

Received: 1 May 2015 / Accepted: 8 June 2015/Published online: 11 July 2015

(C) Springer International Publishing Switzerland 2015

\begin{abstract}
A fundamental index of channel shape is the form ratio (w/d) which is determined by energy-load relation and bank and bed materials of the channel concerned. Average river channels tend to develop their channel-cross sectional form in a way to produce an approximate equilibrium between the channel and the water and sediment it transport. But how far it is deviated from the ideal cross-sectional form is determined only by knowing the ideal form which was calculated ' 2 ' by Hickin (2004) for rectangular channel. This ideal cross-sectional form of 'maximum efficiency' is virtually a theoretical one and by attaining of which a river transports its water and load with least friction with its bed. But ideal form ratios for triangular and semicircular channels have not been calculated earlier. Present paper has found out ideal form ratios 2.544 and 2.31 for semicircular and triangular channels respectively.
\end{abstract}

Keywords Form-ratio - Ideal channel form - Hydraulic radius - Wetted perimeter - Semicircular channel .

Triangular channel

\section{Introduction}

Width:depth ratio (w/d), the most important indicator of channel form is not only a mere numeric fraction. The controlling influence of discharge upon channel form, flow resistance and flow velocity is explored in the concept of

Balai Chandra Das

balaidaskgc@rediffmail.com; drbalaidaskgc@gmail.com

1 P.G. Department of Geography, Krishnagar Govt. College, Nadia 741101, West Bengal, India hydraulic geometry (Huggett 2007). Width:depth (w/d) ratio of a river increases downstream. Moreover, w/d ratio is a good reflector of driving variables (discharge, quantity and size of sediment load) and boundary conditions (valley confinement, channel substrate, valley slope and riparian vegetation) that controls the form of a channel reach (Charlton 2008). A river with given slope tries to shape its channel to minimize the flow resistance. It is estimated that $95 \%$ of a river's energy is used in overcoming flow resistance, leaving just $5 \%$ to carry out geomorphological work (Charlton 2008). Flow resistance is determined by channel shape and an ideal channel reach that attain a shape of minimum flow resistance is called most efficient channel. Cross-sectional form of a river's channel is primarily adjusted by bed and bank erosion (Charlton 2008) and lateral channel migration (Simon and Castro 2003). Width/depth ratio represents dominant measures of channel response (Simon 1992; Simon and Darby 1997) and w/d alone does not define cross-sectional shape (Hey 1978). Form ratio w/d or $w / d_{\max }$ (Schumm 1960), section asymmetry $a_{1} / a_{r}$ (Milne 1979), channel asymmetry (Knighton 1981) regarding cross-sectional form give absolute measure. For study of channel's cross-sectional form, knowing of ideal form-ratio is indispensable (Das 2014) and Hickin (2004) calculated it '2' for rectangular channel. But ideal form-ratios for semicircular and rectangular channels are not yet known. That is why ideal values of form-ratio of semicircular and rectangular channels are calculated in this paper. At the last section of findings and discussions, ideal form ratio $\left(\dot{\mathrm{f}}_{\mathrm{r}}\right)$ was tested to 29 cross-sections to have a comparative picture of ideal form ratio and observed form ratio.

The conventional belief of the v-shaped cross-sectional form of the rivers is far from the reality (Sen 1993). 
Circular (Leopold and Wolman 1969) and parabolic (Lane 1955) forms are also theoretical. Rather trapizoidal form represents the reality (Sen 1993). But all these forms, whether theoretical or practical, are not obvious for the all channels or entire reach of a same channel. Straight course of a river is impossible (Leopold 1966) which makes another impossibility of uniformity of cross-sectional form of the channel. Width increases faster than depth in downstream and cross-sectional form becomes increasingly rectangular (Sen 1993). But sometimes opposite is also the reality (Knighton 1998; Das 2013).

The conditions for efficiency of the cross-sectional characteristics of the channels are closely related to their capacity of maximum flow. Maximum flow (water and sediment load) is only possible when the cross-sectional form attains the semi-circular or parabolic shape (Knighton 1998) or equilateral-triangular or rectangular (Hickin 2004) shape. These shapes generate the minimum turbulence and shear stress hence channel becomes the 'most efficient'. Thus ideal channel form is considered as the 'best conveyance characteristics' (Crickmay 1974). Relationship between channel form and processes operating in the channels were studied as hydraulic geometry by Leopold and Maddock (1953), Wolman (1955), Leopold and Miller (1956) and others. They computed crosssectional variables of mean-depth (d) and width (w) in terms of discharge $(\mathrm{Q})$.

$\mathrm{W}={ }_{\mathrm{a}} \mathrm{Q}^{\mathrm{b}}$ and $\mathrm{d}={ }_{\mathrm{c}} \mathrm{Q}^{\mathrm{f}}$

Different average exponent values for ${ }^{\mathrm{b}}$ and ${ }^{\mathrm{f}}$ of different rivers have been calculated by Leopold and Maddock (1953), Wolman (1955), Leopold and Miller (1956), Lewis (1969), Wilcock (1971) and Harvey (1975). So again, w/d ratio bears much more importance than a mere form ratio of a channel's cross-section. Present paper was aimed in modeling ideal form ratio of semicircular and triangular channel to compare with real channels. To test the ideal form ratio, 11 cross-sections of a river and 18 cross-sections of an ox-bow lake were taken and compared.

\section{Methodology}

Manning (1891) flow resistance equation $v=(1 / \tau) R_{h}^{2 / 3} S_{b}^{1 / 2}$ (Simon and Castro 2003) suggests that flow resistance determines the velocity of a river. Flow resistance in turn is determined by channel form. With given volume; velocity is proportional to hydraulic radius $\left(\mathrm{R}_{\mathrm{h}}^{2 / 3}\right)$ and slope $\left(\mathrm{S}^{1 / 2}\right)$ but inversely proportional to shear stress $(\tau)$. Shear stress (Fig. 1) is calculated as:

$\tau=\gamma D S$

(Knighton 1998; Richards 1982; Chanson 2004) where, $\tau=$ Shear Stress $\left(\mathrm{N} / \mathrm{m}^{2}\right), \gamma=$ Weight Density of Water

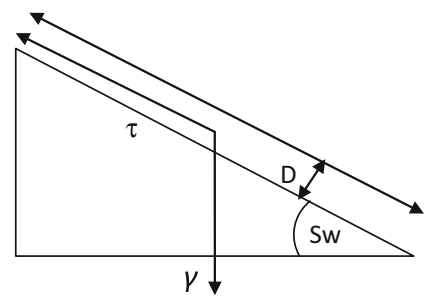

Fig. 1 Shear stress ' $\tau$ ' of a stream of water depth ' $D$ ', slope ' $S w$ ' and weight density of water ' $\gamma$ '

$\left(\mathrm{N} / \mathrm{m}^{3}, \mathrm{lb} / \mathrm{ft}^{3}\right), \quad \mathrm{D}=$ Average water depth $(\mathrm{m}, \mathrm{ft})$ and $\mathrm{S}=$ Water Surface slope $(\mathrm{m} / \mathrm{m}, \mathrm{ft} / \mathrm{ft})$.

However, to find out channel form of maximum efficiency, computation of minimum shear stress or flow resistance is essential. Because where the shear stress is the least, channel is maximum efficient. With given slope, a minimum flow resistance is only possible when hydraulic radius is the maximum. Hydraulic radius is defined as cross-sectional area (A) divided by wetted perimeter (P). To find out lowest wetted perimeter of a cross-section with given cross-sectional area, three alternatives model shapes were considered against each of the semicircular and triangular channel. Maximum hydraulic radius (A/P) or minimum flow resistance from channels with given crosssectional area was calculated using trigonometry, method of bisection and Pythagorean Theorem.

\section{Findings and discussions}

\section{The most efficient semicircular cross-section}

Channel with given cross-sectional area (A) and slope (S) having highest hydraulic radius is the ideal channel form with maximum efficiency. Let cross-sectional shape be semicircular (Fig. 2), minor segment (Fig. 3) and major segment (Fig. 4) of a circle. In all cases, cross-sectional area ' $\mathrm{A}$ ' is constant but lengths of wetted perimeters vary and represented by $S_{1}, S_{2}$ and $S_{3}$ respectively. First type of semicircular channel has a width of 2 r, second type of channel has a width of $4 \mathrm{r}$ and third type of channel has a width of $r$. Different channel widths OP is represented by the letter ' $l$ '. Now let ratio of wetted perimeters of three types of channel be determined.

Fig. 2 Semicircular cross-sectional form with constant area (A) but minimum wetted perimeter $(\mathrm{S} 1=\pi \mathrm{r})$ and medium width $(2 \mathrm{r})$

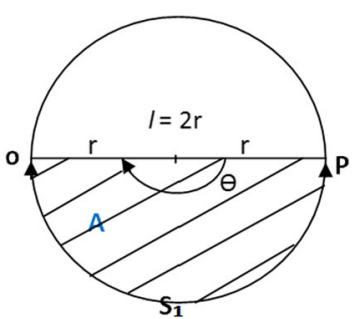




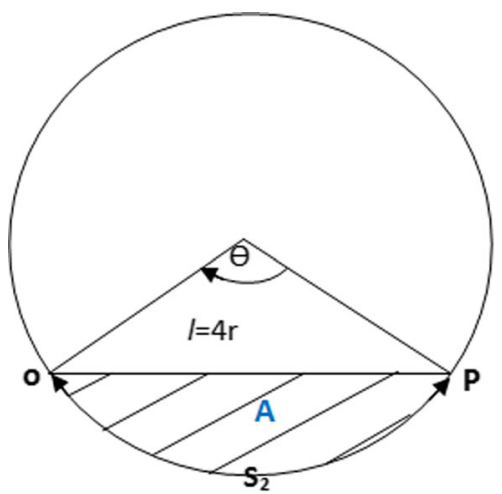

Fig. 3 Minor segment cross-sectional form with constant area $(A)$ but maximum wetted perimeter $(S 2)$ and maximum width (4r)

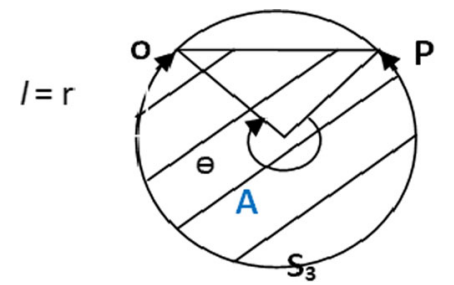

Fig. 4 Major segment cross-sectional form with constant area $(A)$ but medium wetted perimeter $(S 3)$ and minimum width (r)

In any case,

Constant area

$$
\begin{aligned}
A & =\frac{\pi r^{2}}{2 \pi} \theta-\frac{1}{2} r^{2} \sin \theta \\
& =\frac{1}{2} r^{2}(\theta-\sin \theta)
\end{aligned}
$$

Now $\frac{l}{\sin \theta}=\frac{r}{\sin \left(\frac{\pi}{2}-\frac{\theta}{2}\right)}$

Or, $r=\frac{l}{2 \sin \frac{\theta}{2}}$

Therefore, $A=\frac{l^{2}}{8 \sin ^{2} \frac{\theta}{2}}(\theta-\sin \theta)$

Or, $(\theta-\sin \theta)=\left(\frac{8 A}{l^{2}}\right) \sin ^{2} \frac{\theta}{2}=0$

From this equation the value of $\theta$ for a given value of $l$ can be calculated. Then the value of $\mathrm{s}$ can be extracted from the relation $S=r \theta$ as

$S=\frac{l \theta}{2 \sin \frac{\theta}{2}}$

In first case $l=2 r, \mathrm{~A}=\pi r^{2} / 2$ and $\mathrm{S}_{1}=\pi \mathrm{r}$

In second case $l=4 \mathrm{r}, \mathrm{A}=\pi \mathrm{r}^{2} / 2$

From Eq. (2), $\theta-\sin \theta-\frac{8 \frac{\pi r^{2}}{2}}{16 r^{2}} \sin ^{2} \frac{\theta}{2}=0$

or, $\theta-\sin \theta-\frac{\pi}{4} \sin ^{2} \frac{\theta}{2}=0$

Solving by the 'method of bisection', one can get $\theta=1.12798$ which is correct upto 5 decimal places.

Now from Eq. (3),

$\mathrm{S} 2=\frac{4 r \times 1.12798}{2 \operatorname{Sin} 0.56399} \simeq 4.2201986929 r$

$\mathrm{S}_{2} / \mathrm{S}_{1}=\frac{4.2201986929}{\pi} \simeq 1.34333$

In third case $l=\mathrm{r}, A=\pi \mathrm{r}^{2} / 2$

From Eq. (2), $\theta-\sin \theta-4 \pi \sin ^{2} \theta / 2=0$

or, $\theta=4.79125$ which is correct upto 5 decimal places.

Now from Eq. (3), $S_{3} \simeq 3.52981538 \mathrm{r}$

Therefore $\mathrm{S}_{3} / \mathrm{S}_{1}=3.52981538 / \pi \simeq 1.2357$

Hence, $\mathrm{S}_{1}: \mathrm{S}_{2}: \mathrm{S}_{3}=1: 1.34333: 1.12357$

Therefore, semicircular form is the most efficient ideal cross-sectional form, having 'best conveyance characteristics' with minimum wetted perimeter and maximum hydraulic radius.

\section{Ideal width (ẃ) and width index (Iw)}

Ideal width (w') provides tool to compare width of a natural channel with given area to that of the ideal width which the channel tries to attain to be most efficient. $w$ is defined as (2r) and width index $\left(I_{w}\right)$ is defined as $I_{w}=w / w$ w.

Where $\mathrm{w}=$ observed width of the channel

$r=\sqrt{2 \mathrm{~A} / \pi} \quad(\mathrm{A}=$ cross-sectional area of

$\times$ semi-circular channel and expressed as $\mathrm{A}=\pi \mathrm{r}^{2} / 2$ )

Derivation of w:

$\mathrm{A}=\pi \mathrm{r}^{2} / 2$

Or, $\mathfrak{w}^{\prime}=2 r=2 \times 0.798 \sqrt{A} \quad\left[\right.$ as $\left.\mathfrak{w}^{\prime}=2 \mathrm{r}\right]$

Or, $\mathrm{w}^{\prime}=1.595 \sqrt{A}$

Width index $\left(\mathrm{I}_{\mathrm{w}}\right)$ is a numerical tool to compare the shape of the river cross-sectional form, whether its width matches the width of most efficient channel or how much deviated from it. If $I_{w}=1$, the width matches perfectly with the width of a most efficient channel. If $\mathrm{I}_{\mathrm{w}}>1$, it indicates wider unconfined channel with negligible slope, non-cohesive substrate and lack of riparian vegetation (Charlton 2008). When $I_{w}<1$, then the channel is narrower with confined channel, steeper slope, cohesive substrate and or presence of riparian vegetation. In both cases, where $I_{w}>1$ or $I_{w}<1$, channels are less efficient than ideal channel. 




Ideal depth (L) provides tool to compare depth of a natural channel with given area (A) to that of the ideal depth which the channel tries to attain to be most efficient.

D is defined as $\mathrm{A} / \mathrm{w}$ and depth index $\left(\mathrm{I}_{\mathrm{d}}\right)$ is defined as $\mathrm{d} /$ D.

Where $\mathrm{d}=$ observed mean depth of the channel

Derivation of $\check{\mathrm{D}}$ :

$\hat{\mathrm{D}}=A / 2 \mathrm{r}$

Or, $\hat{D}=\pi \mathrm{r}^{2} / 4 \mathrm{r}$

Or, $\hat{\mathrm{D}}=0.627 \sqrt{A}$

Depth index $\left(\mathrm{I}_{\mathrm{d}}\right)$ is a numerical tool to compare the shape of the river cross-sectional form, whether its depth matches the depth of most efficient channel or how much deviated from it. If $I_{d}=1$, the depth matches perfectly with the depth of a most efficient channel. If $\mathrm{I}_{\mathrm{d}}>1$, it indicates deeper confined channel (Charlton 2008) with steep valley-side slope, cohesive or bed-rock substrate and presence of riparian vegetation. When $I_{d}<1$, then the channel is shallower with non-confined channel, gentle slope, non-cohesive substrate and or absence of riparian vegetation. In both cases, where $I_{d}>1$ or $I_{d}<1$, channels are less efficient than ideal channel.

\section{Ideal form number $\left(\dot{f}_{r}\right)$ and channel-form index $\left(C_{f} I\right)$}

Ideal Form Ratio is defined as

$$
\begin{aligned}
& \dot{\mathrm{f}}_{\mathrm{r}}=\dot{w} / \hat{\mathrm{D}} \\
& \dot{\mathrm{f}}_{\mathrm{r}}=1.595 \sqrt{\mathrm{A}} / 0.627 \sqrt{\mathrm{A}} \\
& \dot{\mathrm{f}}_{\mathrm{r}}=2.544
\end{aligned}
$$

Now Channel-form index $\left(\mathrm{C}_{\mathrm{f}} \mathrm{I}\right)$ is defined as $(\mathrm{w} / \mathrm{d}) / \dot{\mathrm{f}}_{\mathrm{r}}$.

If $\mathrm{C}_{\mathrm{f}} I=1$, channel is ideal and semicircular with maximum efficiency. Higher value indicates aggraded and or shallower channels whereas lower value indicates

Fig. 5 Equilateral triangular cross-sectional form with constant area $(A)$ but minimum wetted perimeter

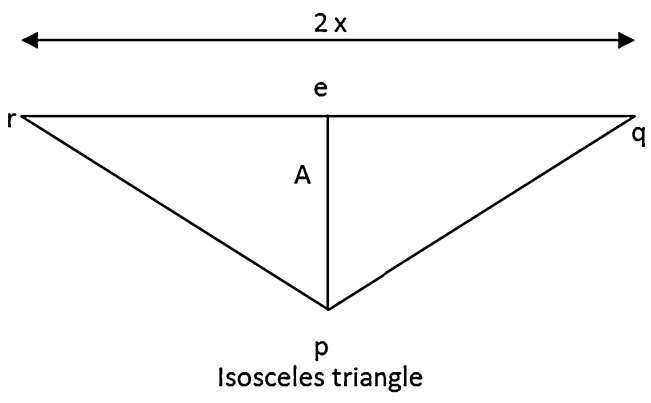

Fig. 6 Wide isosceles triangular cross-sectional form with constant area $(A)$ but medium wetted perimeter

Fig. 7 Narrow isosceles triangular cross-sectional form with constant area $(A)$ but maximum wetted perimeter

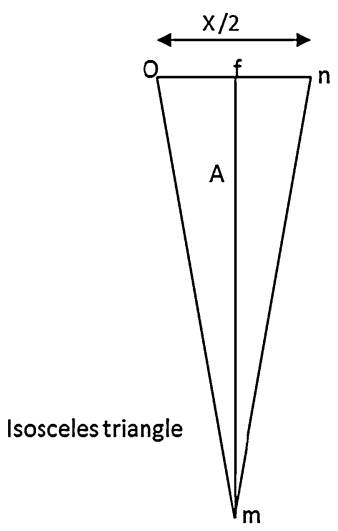

degraded and or deeper channel respectively. In both cases, where $\mathrm{C}_{\mathrm{f}} \mathrm{I}>1$ or $\mathrm{C}_{\mathrm{f}} \mathrm{I}<1$, channels are less efficient than ideal channel.

\section{The most efficient triangular cross-section}

Let cross-sectional shape be equilateral triangle (Fig. 5), isosceles triangular (Fig. 6) and narrow isosceles triangular (Fig. 7). In all cases, cross-sectional area ' $A$ ' is constant and length of wetted perimeter is represented by $2 \mathrm{ac}, 2 \mathrm{pr}$ and 2 mo respectively. First type of triangular channel has a width of $\boldsymbol{x}$, second type of triangular channel has a width of $2 \times$ and third type of triangular channel has a width $x / 2$. Now let ratio of wetted perimeters of three types of channel be determined.

Suppose, area of the equilateral $\Delta$ abc (Fig. 5) is A.

Therefore, $A=\frac{\sqrt{3}}{4}(a b)^{2}$

Or, $A=\frac{\sqrt{3}}{4} x^{2} \quad[\mathrm{as} \mathrm{ab}=\mathrm{x}]$

In $\Delta$ pqr (Fig. 6), area $=\mathrm{A}$ and $\mathrm{pq}=\mathrm{pr}$

Area of $\Delta \mathrm{pqr}=1 / 2(q r \times e p)$

$=1 / 2(2 x \times e p)[a s, 2 x=q r]$

$=\mathrm{x} \times \mathrm{ep}$

Therefore, $x \times e p=\frac{\sqrt{3}}{4} x^{2}$ 
Fig. 8 Sites of 11 cross sections on river Jalangi

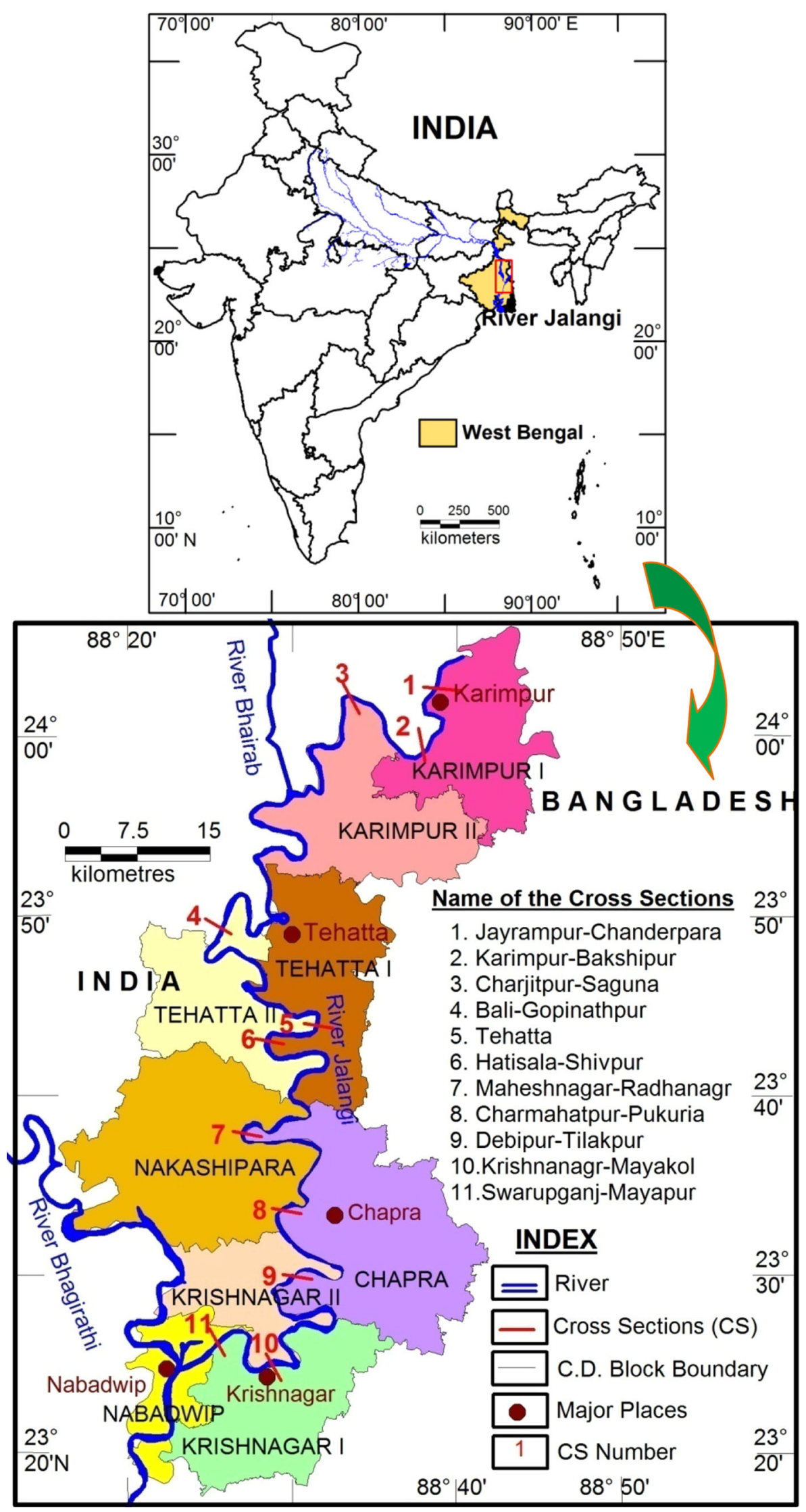




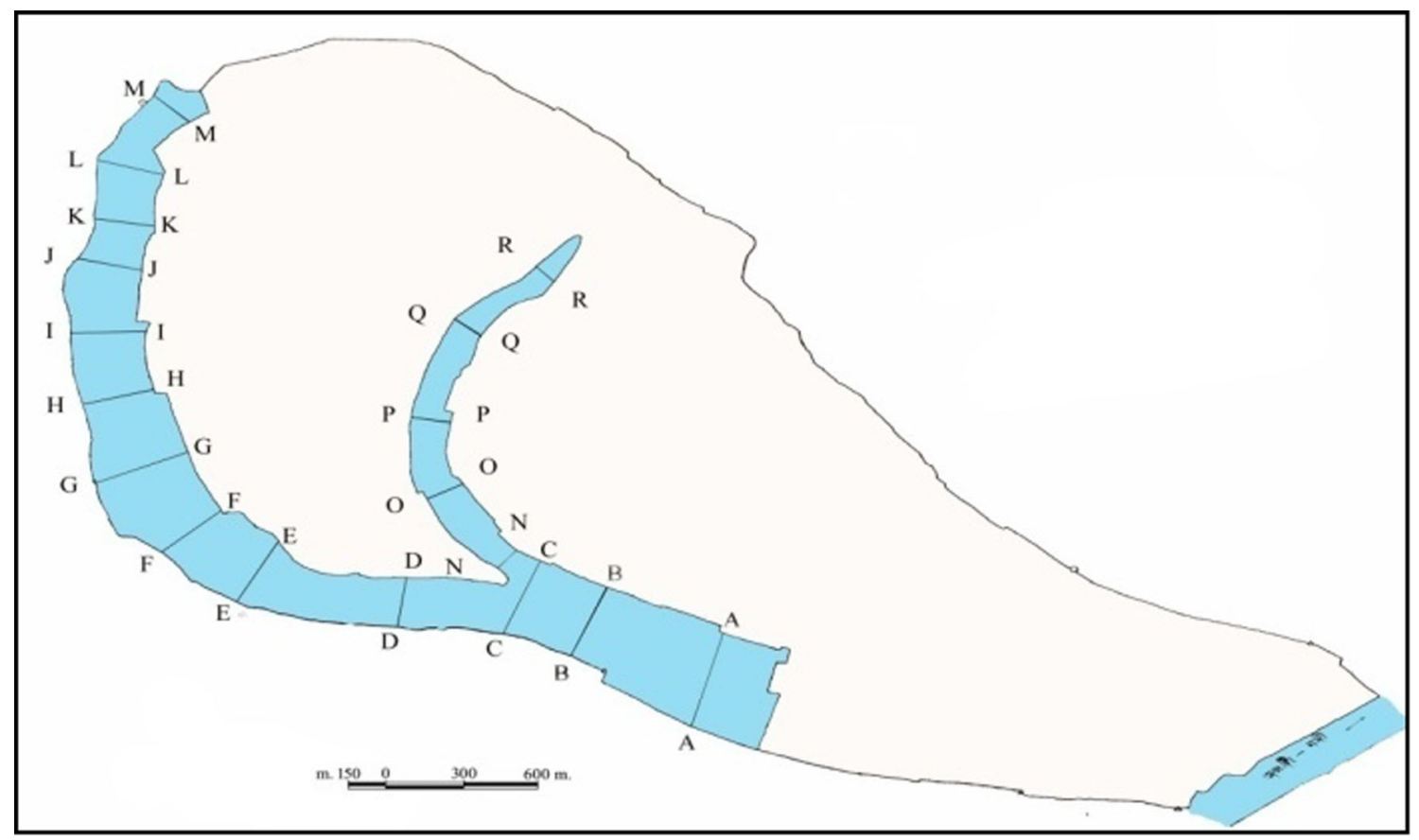

Fig. 9 Sites of cross-sections on the Hansadanga Beel

Or, ep $=\frac{\sqrt{3}}{4} x$

In $\Delta$ per, $(\mathrm{pr})^{2}=(\mathrm{ep})^{2}+(\mathrm{er})^{2}$

$=(\mathrm{ep})^{2}+\mathrm{x}^{2} \quad[$ as er $=\mathrm{x}]$

$=\left(\frac{\sqrt{3}}{4} x\right)^{2}+\mathrm{x}^{2} \quad\left[\right.$ as ep $\left.=\frac{\sqrt{3}}{4} x\right]$

$=\frac{3}{16} x^{2}+x^{2}$

$=\left(3 x^{2}+16 \mathrm{x}^{2}\right) \div 16$

$p r=\frac{\sqrt{19}}{4} x=\frac{4.3}{4} x$

$4 \mathrm{pr}=4.3 \mathrm{x}$

$\frac{x}{4}=\frac{p r}{4.3}$

In $\Delta$ mno (Fig. 7), $\mathrm{mn}=$ mo

Area of $\Delta \mathrm{mno}=1 / 2($ on $\times f m)$

$=\frac{1}{2} \times \frac{x}{2} \times f m[$ as, on $=x / 2]$

$=\frac{x}{4} \times f m$

Now, $=\frac{x}{4} \times f m=\frac{\sqrt{ } 3}{4} x^{2}$ [as Areas of all three triangles are equal] $\mathrm{fm}=\sqrt{ } 3 \mathrm{x}$

In $\Delta$ fmo, $(\mathrm{om})^{2}=(\mathrm{fm})^{2}+(\mathrm{fo})^{2}$

$=(\mathrm{fm})^{2}+(\mathrm{x} / 4)^{2} \quad[$ as fo $=\mathrm{x} / 4]$

$=(\sqrt{ } 3 \mathrm{x})^{2}+(\mathrm{x} / 4)^{2} \quad[$ as fm $=\sqrt{ } 3 \mathrm{x}]$

$=\left(48 x^{2}+x^{2}\right) \div 16$

$\mathrm{om}=7 \mathrm{x} / 4$

Or, $\frac{x}{4}=\frac{o m}{7}$

Therefore,

$\frac{x}{4}=\frac{p r}{4.3}=\frac{o m}{7}=k$

$\mathrm{x}=4 \mathrm{k}, \mathrm{pr}=4.3 \mathrm{k} \quad$ and om $=7 \mathrm{k}$

Therefore, ratio of wetted perimeter of channel types, i.e.

1st : 2nd $: 3 \mathrm{rd}=4: 4.3: 7$

So, hydraulic radius with given cross-sectional area of wide $V$-shaped and narrow $V$-shaped triangular channels are smaller than that of an equilateral triangular channels. Therefore, ideal cross-sectional form of a river having maximum efficiency is either semicircular or equilateral triangular and rectangular with w/d ratio 2:1 (Hickin 2004) as well. 
Table 1 Cross sectional variables of Jalangi River

\begin{tabular}{llllllcc}
\hline Name of CS & $\mathrm{A}$ & $\mathrm{w}$ & $\mathrm{d}$ & $\mathrm{w} / \mathrm{d}$ & $\mathrm{W}=1.595 \sqrt{ } \mathrm{A}$ & $\mathrm{D}=0.672 \sqrt{\mathrm{A}}$ & $\mathrm{C}_{\mathrm{f}} \mathrm{I}=(\mathrm{w} / \mathrm{d}) / \dot{\mathrm{f}}_{\mathrm{r}}$ \\
\hline 1 & 172.21 & 116.64 & 1.47642 & 79.0017 & 20.93099 & 8.818576 & 31.05414 \\
2 & 453.66 & 181.01 & 2.50627 & 72.2229 & 33.97238 & 14.31313 & 28.38949 \\
3 & 30.11 & 47.12 & 0.63901 & 73.7394 & 8.752176 & 3.687437 & 28.98563 \\
4 & 568.9 & 135 & 4.21407 & 32.0355 & 38.04334 & 16.02829 & 12.59257 \\
5 & 524.78 & 98.72 & 5.31584 & 18.5709 & 36.53838 & 15.39423 & 7.299882 \\
6 & 860.22 & 134.2 & 6.40999 & 20.9361 & 46.78056 & 19.70943 & 8.229595 \\
7 & 672.63 & 117.22 & 5.73819 & 20.4281 & 41.3665 & 17.42839 & 8.029898 \\
8 & 1016.32 & 184 & 5.52348 & 33.3123 & 50.84824 & 21.42321 & 13.09447 \\
9 & 687.99 & 144.4 & 4.76447 & 30.3077 & 41.83615 & 17.62627 & 11.91338 \\
10 & 827.68 & 144.04 & 5.74618 & 25.0671 & 45.88724 & 19.33306 & 9.853412 \\
11 & 786.24 & 124.2 & 6.33044 & 19.6195 & 44.72375 & 18.84286 \\
Average & 600.067273 & 129.686 & 4.42403 & 38.6583 & 37.2436 & 15.6914 & 7.712072 \\
SD & 296.0400595 & 37.6657 & 1.997753 & 23.9252 & 12.38747 & 5.219049 \\
CV & 0.493344785 & 0.290437 & 0.451568 & 0.618889 & 0.332607 & 0.332607 & 9.404559 \\
\hline
\end{tabular}

Source: Field survey, 2007-2010

Table 2 Cross sectional variables of Hansadanga Beel (ox-bow lake)

\begin{tabular}{|c|c|c|c|c|c|c|c|}
\hline CS name & A & $\mathrm{w}$ & $\mathrm{d}$ & $\mathrm{w} / \mathrm{d}$ & $\dot{\mathrm{W}}=1.595 \sqrt{ } \mathrm{A}$ & $\check{\mathrm{D}}=0.672 \sqrt{ } \mathrm{A}$ & $\mathrm{C}_{\mathrm{f}} \mathrm{I}=(\mathrm{w} / \mathrm{d}) / \dot{\mathrm{f}}_{\mathrm{r}}$ \\
\hline $\mathrm{A}$ & 151.5802 & 179.5 & 0.844458 & 212.5624 & 19.6373068 & 8.273523617 & 83.55439 \\
\hline BB & 420.9537 & 219.92 & 1.914122 & 114.8934 & 32.7248642 & 13.78752899 & 45.1625 \\
\hline $\mathrm{CC}$ & 512.0287 & 215.71 & 2.37369 & 90.87539 & 36.09174162 & 15.20605039 & 35.72146 \\
\hline DD & 412.3411 & 152.47 & 2.704408 & 56.37833 & 32.38836118 & 13.64575468 & 22.16129 \\
\hline $\mathrm{EE}$ & 482.9629 & 146 & 3.307965 & 44.1359 & 35.05238496 & 14.76815216 & 17.34902 \\
\hline $\mathrm{FF}$ & 498.9046 & 181 & 2.756379 & 65.66586 & 35.62619507 & 15.00990789 & 25.81205 \\
\hline GG & 470.1287 & 203 & 2.315905 & 87.65472 & 34.58351003 & 14.57060736 & 34.45547 \\
\hline $\mathrm{HH}$ & 392.407 & 181 & 2.167994 & 83.48732 & 31.59577849 & 13.31182642 & 32.81734 \\
\hline II & 769.4845 & 255 & 3.017586 & 84.50463 & 44.24463589 & 18.6410002 & 33.21723 \\
\hline JJ & 294.1858 & 186 & 1.581644 & 117.5992 & 27.35719106 & 11.52603912 & 46.22608 \\
\hline KK & 95.584 & 171.7 & 0.55669 & 308.4302 & 15.59384768 & 6.569947112 & 121.2383 \\
\hline LL & 18.435 & 55 & 0.335182 & 164.09 & 6.848291822 & 2.885299125 & 64.50077 \\
\hline MM & 61.93925 & 152.55 & 0.406026 & 375.7149 & 12.55288813 & 5.288740329 & 147.6867 \\
\hline $\mathrm{NN}$ & 136.0183 & 112 & 1.214449 & 92.22289 & 18.60198453 & 7.837325144 & 36.25114 \\
\hline $\mathrm{OO}$ & 196.4173 & 136.5 & 1.438954 & 94.86057 & 22.35375571 & 9.418008676 & 37.28796 \\
\hline PP & 380.7795 & 128 & 2.97484 & 43.02752 & 31.12414868 & 13.11312095 & 16.91333 \\
\hline QQ & 317.8545 & 116 & 2.740125 & 42.33384 & 28.43641669 & 11.98073481 & 16.64066 \\
\hline $\mathrm{RR}$ & 204.9383 & 109.7 & 1.86817 & 58.72057 & 22.83348766 & 9.620127716 & 23.08198 \\
\hline Average & 323.1635 & 161.1694 & 1.917699 & 118.731 & 27.09148834 & 11.41409415 & 46.67098 \\
\hline SD & 195.0544 & 48.07964 & 0.949329 & 92.59937 & 9.663063475 & 4.071209188 & 36.39913 \\
\hline $\mathrm{CV}$ & 0.603578 & 0.298317 & 0.495035 & 0.779909 & 0.356682636 & 0.356682636 & 0.779909 \\
\hline
\end{tabular}

Source: Field survey, January 2015

\section{Ideal width $(\ddot{w})$ and width index $\left(I_{w}\right)$}

Ideal width $(\ddot{w})$ of triangular channel provides tool to compare natural channel width (w) with ideal width which the channel tries to attain to be most efficient.

Derivation of $\ddot{\mathrm{w}}$ :

$\ddot{\mathrm{w}}=x,[x$, is the length of a side of an equilateral triangle $]$
Now, if the cross-sectional area of the concerned channel is ' $A$ ', then

$A=\frac{\sqrt{ } 3}{4} x^{2}$

Or, $x^{2}=2.3094 A$ 
Fig. 10 Location of Hansadanga Beel on the right bank of the river Jalangi

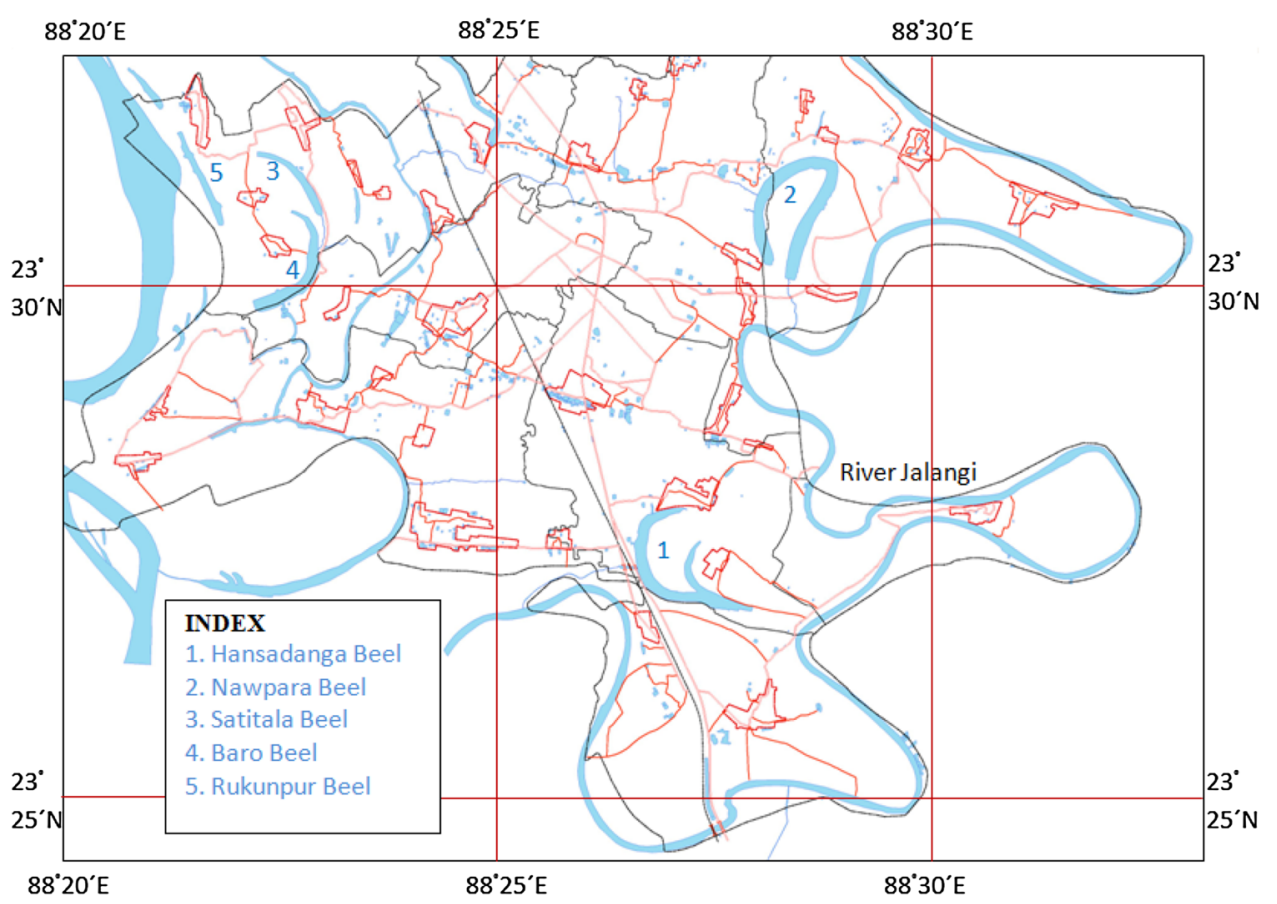

Or $x=1.52 \sqrt{A}$

Or, $\ddot{\mathrm{w}}=1.52 \sqrt{A}$

Width index $\left(\mathrm{I}_{\mathrm{w}}\right)=\mathrm{w} / \ddot{\mathrm{w}}$.

Significance of width index in triangular channel form is as width index in semicircular channel form (see under the section "Ideal width (ẃ) and width index (Iw)")

\section{Ideal depth $(\underline{d})$ and depth index $\left(I_{d}\right)$}

Ideal depth $(\underline{d})$ provides tool to compare mean depth (d) of a natural channel of given area to that of the ideal mean depth $(\underline{d})$ which the channel tries to attain to be most efficient.

$\underline{d}$ is defined as $\mathrm{A} / \mathrm{w}$ and depth index $\left(\mathrm{I}_{\mathrm{d}}\right)$ is defined as $\mathrm{I}_{\mathrm{d}}=\mathrm{d} / \underline{\mathrm{d}}$

Derivation of $\underline{d}$ :

$\underline{\mathrm{d}}=\mathrm{A} / 1.52 \sqrt{A}$

Or, $\underline{\mathrm{d}}=\sqrt{\mathrm{A}} / 1.52$

Significance of depth index in triangular channel form is as depth index in semicircular channel form.

Ideal form number $\left(\Delta_{3}\right)$ and channel-form index $\left(C_{f} I\right)$

$\Delta_{3}=\ddot{\mathrm{w}} / \underline{\mathrm{d}}$

Or, $\Delta_{3}=\frac{1.52 \sqrt{\mathrm{A}}}{\sqrt{\mathrm{A}} / 1.52}$

Or, $\Delta_{3}=2.31$
Now triangular Channel-form index $\left(\mathrm{C}_{\mathrm{f}} \mathrm{I}_{\Delta}\right)$ is defined as $(\mathrm{w} / \mathrm{d}) / \Delta 3$.

If $C_{f} I=1$, channel is ideal and equilateral triangular with maximum efficiency. Lesser the value, narrower the shape and implies the channel of upper course or youth stage. If the value is greater than 1 , it implies the wider $\mathrm{v}$-shaped channel of lower reach or old stage.

\section{Testing of $C_{f} I$ on river channel and ox-bow lake channel}

$\mathrm{C}_{\mathrm{f}} \mathrm{I}$ was applied to 29 cross sections of channels. For this empirical test, 11 sections were selected on river Jalangi (Fig. 8), a deltaic distributary of the river Ganges and 18 cross-sections were selected on an ox-bow lake 'Hansadanga Beel' (Fig. 9) which is originated during late eighteenth or early nineteenth century (Das 2012) as a neck cutoff of a meander (Fig. 10) of the river Jalangi.

Result shows that average form ratio (w/d) of the river Jalangi is 38.6583 (Table 1 ) and $\mathrm{C}_{\mathrm{f}} \mathrm{I}$ is 15.2 which imply that the width/depth ratio is 15.2 times greater than the ideal form ratio (2.55). On the other hand, average form ratio of the ox-bow lake is 118.731 (Table 2) and $\mathrm{C}_{\mathrm{f}} \mathrm{I}$ is 46.7. It implies that ox-bow lake channel is many times wider and shallower than the river channel. The finding is very interesting because although there is a great difference between two sets of observations, both set of cross sections are basically on the river Jalangi as the ox-bow lake is also a rejected channel of the same river. $\mathrm{C}_{\mathrm{f}} \mathrm{I}$ of the ox-bow lake is many folds higher than the river because it 
has lost its depth heavily due to severe silting and no scouring. But the river scours its bed annually during floods.

\section{Conclusions}

The ratio of width to depth is the function of channel shape. But mere width:depth ratio (w/d) does not define crosssectional shape (Hey 1978) even though it is a widely used index. So to have comparison, instead of simple width/ depth ratio, Ideal Form Numbers $\dot{f}_{\boldsymbol{r}}=2.544$ or $\Delta_{3}=2.31$ gives better explanation. Moreover, with a given area of channel cross-section, how far its width and depth are deviated from the ideal width or depth can be determined by ideal numbers $w^{\prime}=1.595 \sqrt{ } \mathrm{A}$ or $\quad \dot{w}=1.52 \sqrt{ } A$ and $\check{\mathrm{D}}=0.627 \sqrt{ } \mathrm{A}$ or $\underline{\mathrm{d}}=\sqrt{\mathrm{A}} / 1.52$ respectively.

Acknowledgments Numbers 2.544 in Eq. (6) and 2.31 in Eq. (13) are dedicated to Professor Sandip Kumar Chawdhury and named as sandip number-1 and sandip number-2 respectively.

\section{References}

Chanson H (2004) The hydraulics of open channel flow: an introduction, 2e. Elsevier, Amsterdam, p 45

Charlton R (2008) Fundamentals of fluvial geomorphology. Routledge, New York, pp 4-7

Crickmay HC (1974) The work of the river. Mcmillan Press Ltd, London

Das BC (2012) Origin of beels in Moribund-Delta of West Bengal: a case study on beels of C. D. Block Krishnagar-II, Conscientia, vol 2, no 1, pp 40-45. ISSN-2278-6554

Das BC (2013) Changes and deterioration of the course of river Jalangi and its impact on the people living on its banks, Nadia, West Bengal: Ph.D. Thesis. Kolkata, University Of Calcutta

Das BC (2014) Asymmetry of river channel cross-sections: a review. Int J Res Manag Sci Technol (E-ISSN: 2321-3264) 2(3):15-18

Harvey AM (1975) Some aspects of the relations between channel characteristics and riffle spacing in meandring streams. Am J Sci 275:470-478

Hey RD (1978) Determinate hydraulic geometry of river channels. J Hydraul Div 104(HY4):365-379
Hickin EJ (2004) River hydraulics and channel form. Wiley, Chichester, p 6.2

Huggett RJ (2007) Fundamentals of geomorphology. Routledge, London, $\mathrm{p} 227$

Knighton AD (1981) A symmetry of river channel cross-sections: part 1. Quantitative indices. Earth Surf Process Landf VI:581-588

Knighton AD (1998) Fluvial forms and processes a new perspective. Arnold, London

Lane EW (1955) Design of stable alluvial channels. Trans Am Soc Civ Eng 120(2776):1234-1260

Leopold LB (1966) River meanders. Sci Am 214(6):60

Leopold LB Jr, Maddock T (1953) The hydraulic geometry of stream channels and some physiographic implications. U S Geol Surv Prof Pap 500A:252

Leopold LP, Miller J (1956) Ephemeral streams-hydraulic factors and their relation to the drainage net. United States Geological Survey Professional Paper 282A, pp 57-91

Leopold LB, Wolman MG (1969) Fluvial processes in geomorphology. Eurasia Publishing House Pvt. Ltd., Reprint, New Delhi

Lewis LA (1969) Some fluvial geomorphic characteristics of the Manati Basin, Puertorico. Ann Assoc Am Geogr 59:280-293

Manning R (1891) On the flow of water in open channels and pipes. Trans Inst Civ Eng Irel 20:161-207

Milne JA (1979) The morphological relationships of bends in confined stream channels in upland Britain (vol Geographical Approceaches To Fluvial Processes). In: Pitty AF (ed) Geobooks, Norwich

Richards K (1982) Rivers forms and processes in alluvial channels. The Blackburn Press, New Jersey, p 63

Schumm SA (1960) The shape of alluvial channels in relation to sediment type, professional paper. U S Geol Surv 352B:17-30

Sen PK (1993) Geomorphological analysis of drainage basins. The University of Burdwan, Burdwan

Simon A (1992) Energy, time and channel evolution in catastrophically disturbed fluvial systems. Geomorphol 5:345-372

Simon AE, Darby S (1997) Process-form interactions in unstable sand bed river channels: a numerical modelling approach. Geomorphology 21:85-106

Simon A, Castro J (2003) Measurement and analysis of alluvial channel form. In: Kondolf GM, Piégay H (eds) Tools in fluvial geomorphology. Wiley, pp 291-322

Wilcock DN (1971) Investigation into the relations between bedload transport and channel shape. Bull Geol Soc Am 82:2159-2176

Wolman MG (1955) The natural channel of Brandywine Creek, Pennsylvania. United States Geological Survey Professional Paper, 271 